\title{
Control of Apple Blue Mold by the Antagonistic Yeast Pichia anomala Strain K: Screening of UV Protectants for Preharvest Application
}

Rachid Lahlali, AAFC, Saskatoon Research Centre, 107 Science Place, Saskatoon, S7N 0X2, Saskatchewan, Canada, and Plant Pathology Unit, Gembloux Agro-Bio Tech, University of Liege, Passage de Deportes 2, 5030 Gembloux, Belgium; Yves Brostaux, Applied Statistics, Mathematics and Computer Science Unit, Gembloux Agro-Bio Tech, University of Liege; and M. Haissam Jijakli, Plant Pathology Unit, Gembloux Agro-Bio Tech, University of Liege

\begin{abstract}
Lahlali, R., Brostaux, Y., and Jijakli, M. H. 2011. Control of apple blue mold by the antagonistic yeast Pichia anomala strain K: Screening of UV protectants for preharvest application. Plant Dis. 95:311-316.

When applied preharvest, antagonistic yeasts that act as biocontrol agents of postharvest fruit diseases must survive the environmental conditions in the field. In particular, UV-B radiation (280 to $320 \mathrm{~nm}$ ) can greatly reduce their survival and effectiveness. The influence of artificial UV-B radiation on Pichia anomala strain K, an antagonistic yeast with potential for control of postharvest fruit diseases, was evaluated in vitro and in vivo. The in vitro 50 and $90 \%$ lethal dose values were 0.89 and $1.6 \mathrm{Kj} / \mathrm{m}^{2}$, respectively, whereas lethal values in vivo were 3.2 and $5.76 \mathrm{Kj} / \mathrm{m}^{2}$, respectively. UV protectants tested in combination with strain $\mathrm{K}$ included congo red, tryptophan, riboflavin, lignin, casein, gelatine, folic acid, tyrosine, and four mixtures. Riboflavin, folic acid, and the mixtures $1 \%$ folic acid $+0.5 \%$ tyrosine $+0.5 \%$

riboflavin (formula 2), $0.5 \%$ folic acid $+1 \%$ tyrosine $+0.5 \%$ riboflavin (formula 3), and $0.5 \%$ folic acid $+0.5 \%$ tyrosine $+1 \%$ riboflavin (formula 4) reduced yeast mortality caused by UV-B radiation in petri dish assays. Riboflavin, folic acid, gelatine, lignin, and tyrosine reduced yeast mortality caused by UV-B radiation on apple fruit surfaces. With the exception of lignin and folic acid, none of the compounds or mixtures increased significantly the ability of strain $\mathrm{K}$ to control the postharvest pathogen Penicillium expansum on wounded apple fruit. In contrast, casein, gelatine, tyrosine, congo red, riboflavin, and formulas 1 to 4 significantly reduced the effectiveness of strain K. Further investigations are justified to verify a potential benefit of lignin and folic acid for UV protection of strain $\mathrm{K}$ in preharvest applications.
\end{abstract}

Fruit diseases caused by postharvest pathogens can result in $25 \%$ or more decay (10), depending on the kind of fruit, the pathogen, and storage conditions (1). Such losses are particularly high in developing countries (48) and reflect reductions in the quality and quantity of marketable fruit. Methods for controlling postharvest diseases include careful handling during harvest, cooling of the fruit after harvest, maintaining controlled atmosphere in storage, heat treatment (15), cleaning and disinfecting storage containers and shipping cars, providing ventilation to control relative humidity, and disposing of infected fruit (1). Although these control methods are helpful, they are usually insufficient in preventing fungal infection and, thus, application of fungicides has been the primary means of controlling postharvest diseases caused by fungi (12).

The development of resistance in fungal pathogens to fungicides $(4,20,38,45,46)$ and the growing public concern over hazards associated with pesticide application $(30,44,49)$ have resulted in a significant interest in alternative methods for disease control. One alternative method is biological control, which is attractive for the control of postharvest infections because it leaves no chemical residue on the treated fruit $(35,46,47)$. Microorganisms that are antagonistic toward plant-pathogenic fungi and other pests are termed biocontrol agents and include nonpathogenic bacteria, yeast, and fungi. These biocontrol agents are easily cultured in the developing world for use by local specialists (liquid fermentation systems) or farmers themselves using semi-solid cultivation on rice, cassava, wheat bran, or a similar substrate (19). Antagonistic microorganisms that can be produced include Trichoderma viride, Pseudomo-

Corresponding authors: M. H. Jijakli, E-mail: MH.Jijakli@ulg.ac.be; and R. Lahlali, E-mail: lahlali.r@gmail.com

Accepted for publication 28 October 2010.

doi:10.1094/PDIS-04-10-0265

(C) 2011 The American Phytopathological Society nas fluorescens, Azospirillum and Phosphobacter spp., and mycorrhizal fungi (39).

The yeast Pichia anomala strain K (strain K) was isolated from the surface of apple fruit and was shown to have antagonistic activity against the plant-pathogenic fungi Penicillium expansum and Botrytis cinerea (26). Strain K was reported to be effective against $P$. expansum, $B$. cinerea, and other postharvest pathogens of fruit $(26,32)$. Its mechanism of action in controlling $B$. cinerea on apple includes competition for nutrients and mycoparasitism $(14,25,26,33)$. Several monitoring systems have been developed to track the population dynamics of strain $\mathrm{K}$ on apple fruit $(9,37)$.

For biological control of postharvest fruit infections, biocontrol agents have been applied alone or in combination with other safety pest and disease control methods before or after harvest (25). The success of preharvest application of yeasts and other microorganisms for biocontrol of postharvest diseases can be greatly affected by temperature, humidity, rain, and UV-B radiation (30). Ippolito and Nigro (24) also reported that the orchard microenvironment can affect the viability of biocontrol agents. The effects of water activity and temperature on strain $\mathrm{K}$ have been determined (28), and Lahlali et al. (31) proposed and validated a model for predicting the population density of strain $\mathrm{K}$ on apple fruit surface in relation to the microenvironment $48 \mathrm{~h}$ after the yeast had been applied in orchards; yeast density on fruit was more affected by relative humidity than by temperature. A formulation of Candida oleophila strain $\mathrm{O}$ based on skimmed milk reduced the yeast's sensitivity to the orchard microenvironment (29).

The adverse effect of sunlight on biocontrol agents may require that UV protectants be included in the agent formulation. Such UV protectants include riboflavin, para-aminobenzoic acid, ascorbic acid, folic acid, uric acid, casein, tyrosine, gelatine, and lignin $(2,11,15,17,18,21-23,27,42)$. To the best of our knowledge, there are no reports about the influence of UV-B radiation on the biocontrol agent's survival when applied preharvest for postharvest disease management. The objectives of this study were to assess the influence of UV-B radiation on the in vitro and in vivo survival of strain $\mathrm{K}$ and to evaluate the ability of UV protectants to protect 
strain $\mathrm{K}$ against UV-B radiation. The efficacy of strain $\mathrm{K}$ in combination with UV protectants was determined on apple fruit inoculated with the postharvest pathogen $P$. expansum under controlled conditions.

\section{Materials and Methods}

Microorganisms. Pichia anomala strain K (referred to as strain $\mathrm{K}$ in this study) was isolated from the surface of cv. Golden Delicious apple fruit at the Plant Pathology Unit of Gembloux AgroBio Tech (Belgium) and was identified to the species level by the Industrial Fungi \& Yeast Collection (BCCMTM/MUCL, Louvainla-Neuve, Belgium). Stock cultures obtained from the Industrial Fungi \& Yeast Collection were stored at $4{ }^{\circ} \mathrm{C}$ on potato dextrose agar (PDA; Merck, Darmstadt, Germany) in petri dishes. Before each experiment, this strain was grown on PDA at $25^{\circ} \mathrm{C}$ for three successive subcultures under the same conditions in 24-h intervals. Before application to apple, yeast colonies were flooded with sterile distilled water (SDW) and scraped from petri dishes. The final concentration was adjusted to $1 \times 10^{7}$ or $1 \times 10^{8} \mathrm{CFU} / \mathrm{ml}$ using optical density measurements at $595 \mathrm{~nm}$ with an UltrospecII spectrophotometer (LKB Biochron Ltd., Uppsala, Sweden; 25).

Penicillium expansum (strain vs2) was isolated from decayed apple fruit (Plant Pathology Unit, Gembloux Agro-Bio Tech, Belgium). For long-term storage, the strain was placed at $-80^{\circ} \mathrm{C}$ in tubes containing $25 \%$ glycerol. Conidial suspensions in SDW containing $0.05 \%$ Tween 20 were prepared from 9- to 11-day-old cultures grown at $25^{\circ} \mathrm{C}$. The final desired concentration of $1 \times 10^{4}$ spores $/ \mathrm{ml}$ was determined with a Bürker cell counter.

In vitro and in vivo influence of $U V-B$ radiation on survival of strain K. Four Philips Ultraviolet-B lamps (LT 40 W/12 RSNetherlands) were used to generate UV-B radiation. The lamps were positioned $25 \mathrm{~cm}$ above the petri dishes and apple fruit. In the in vitro experiments, the $1 \times 10^{8} \mathrm{CFU} / \mathrm{ml}$ petri dish lids were replaced by Clarifoil Standard cellulose diacetate filters of $75 \mu \mathrm{m}$ in thickness (Clarifoil, Puteaux Cedex, France). Prior to the experiment, these filters were exposed to UV-B radiation for more than $100 \mathrm{~h}$ so that they would block UV-C radiation and wavelengths below approximately $292 \mathrm{~nm}$. The treated filters blocked UV-C radiation and wavelengths $<292 \mathrm{~nm}$ for 15 days (data not shown). Exposure times were converted to UV-B radiation doses and natural sunlight as previously described by Melendez (34).

Suspensions of strain K $(20 \mathrm{ml})$ adjusted to $1 \times 10^{7} \mathrm{CFU} / \mathrm{ml}$ in SDW were exposed to UV-B radiation for $0 \mathrm{~h}, 0.5 \mathrm{~h}\left(0.46 \mathrm{Kj} / \mathrm{m}^{2}\right)$,

Table 1. Incidence (\%) of decayed apple fruit and percentage (\%) of infected wounds of fruit by Penicillium expansum in strain $\mathrm{K}$ with and without $\mathrm{UV}$ protectants after incubation period of 7 days at $25^{\circ} \mathrm{C}^{\mathrm{y}}$

\begin{tabular}{lcc}
\hline Treatment & $\begin{array}{c}\text { Incidence of decayed } \\
\text { apple fruit } \mathbf{\%})\end{array}$ & $\begin{array}{c}\text { Infected wounds } \\
\text { of fruit }(\%)\end{array}$ \\
\hline Strain K & $13.3 \mathrm{~d}$ & $10.0 \mathrm{~h}$ \\
Strain K + CR & $26.6 \mathrm{bc}$ & $23.3 \mathrm{efg}$ \\
Strain K + TRY & $20.0 \mathrm{c}$ & $16.6 \mathrm{~g}$ \\
Strain K + riboflavin & $33.3 \mathrm{bc}$ & $30.0 \mathrm{defg}$ \\
Strain K + lignin & $0.0 \mathrm{e}$ & $0.0 \mathrm{i}$ \\
Strain K + casein & $60.0 \mathrm{ab}$ & $33.3 \mathrm{cdef}$ \\
Strain K + gelatine & $46.6 \mathrm{abc}$ & $46.6 \mathrm{bcd}$ \\
Strain K + folic acid & $0.0 \mathrm{e}$ & $0.0 \mathrm{i}$ \\
Strain K + tyrosine & $60.0 \mathrm{ab}$ & $60.0 \mathrm{abc}$ \\
Strain K + formula 1 & $20.0 \mathrm{c}$ & $20.0 \mathrm{fg}$ \\
Strain K + formula 2 & $20.0 \mathrm{c}$ & $20.0 \mathrm{fg}$ \\
Strain K + formula 3 & $66.6 \mathrm{ab}$ & $66.6 \mathrm{ab}$ \\
Strain K + formula 4 & $46.6 \mathrm{abc}$ & $40.0 \mathrm{bcde}$ \\
Untreated control & $100 \mathrm{a}$ & $100 \mathrm{a}$ \\
\hline
\end{tabular}

${ }^{y}$ Shown are the mean values of combined datasets of two independent experiments with three replicates for each treatment and five apple fruit per replicate (10 wounds). In column, treatments with the same letters are not significantly different according to Tukey's test $(\alpha=0.05)$.

${ }^{\mathrm{z}} \mathrm{CR}=$ congo red, Try = tryptophan, formula $1=$ formula $1=0.1 \%$ congo red $+0.1 \%$ tryptophan, formula $2=1 \%$ folic acid $+0.5 \%$ tyrosine $+0.5 \%$ riboflavin, formula $3=0.5 \%$ folic acid $+1 \%$ tyrosine $+0.5 \%$ riboflavin, formula $4=0.5 \%$ folic acid $+0.5 \%$ tyrosine $+1 \%$ riboflavin
1 h $\left(0.93 \mathrm{Kj} / \mathrm{m}^{2}\right), 2$ h $\left(1.87 \mathrm{Kj} / \mathrm{m}^{2}\right), 2.5$ h $\left(2.33 \mathrm{Kj} / \mathrm{m}^{2}\right), 3$ h $(2.79$ $\left.\mathrm{Kj} / \mathrm{m}^{2}\right)$, and $4 \mathrm{~h}\left(3.74 \mathrm{Kj} / \mathrm{m}^{2}\right)$ in petri dishes. For each exposure time, an unexposed strain $\mathrm{K}$ was kept in darkness. After exposure to UV-B radiation, each suspension was transferred to a 50-ml Falcon tube and then 10-fold serially diluted in SDW. A 100- $\mu$ l aliquot from each dilution was plated on PDA and then incubated for $72 \mathrm{~h}$ at $25^{\circ} \mathrm{C}$ in a growth chamber before colonies were counted. The results were evaluated as mortality rate (MR, \%) using the formula MR $(\%)=[(\mathrm{UT}-\mathrm{ET}) /(\mathrm{UT})] \times 100$; where $\mathrm{UT}=$ average number of colonies from dishes that were not exposed to $\mathrm{UV}-\mathrm{B}$ radiation and $\mathrm{ET}=$ the number of colonies from dishes that were exposed to UV-B radiation. There were three replicate dishes for each exposure time, and the experiment was conducted twice over time.

In the in vivo experiment, fruit (cv. Golden Delicious) used in the in vivo and biological control assays were bought from a commercial market and stored no longer than 3 months in a cold room at $3^{\circ} \mathrm{C}$ before being used for the bioassays. Selected fruit were free of wounds and rots and as homogeneous as possible in maturity and size. Apple fruit were disinfested in sodium hypochlorite (10\%) for 2 min and then rinsed twice in SDW. After drying, apple fruit were dipped into $400 \mathrm{ml}$ of a suspension of strain $\mathrm{K}\left(1 \times 10^{8}\right.$ $\mathrm{CFU} / \mathrm{ml}$ ) for $2 \mathrm{~min}$ and then dried for $1 \mathrm{~h}$. Fruit were then exposed to UV-B radiation for $0.0 \mathrm{~h}\left(0 \mathrm{Kj} / \mathrm{m}^{2}\right), 1 \mathrm{~h}\left(0.93 \mathrm{Kj} / \mathrm{m}^{2}\right), 2 \mathrm{~h}(1.87$ $\left.\mathrm{Kj} / \mathrm{m}^{2}\right), 3 \mathrm{~h}\left(2.79 \mathrm{Kj} / \mathrm{m}^{2}\right), 4 \mathrm{~h}\left(3.74 \mathrm{Kj} / \mathrm{m}^{2}\right)$, and $5 \mathrm{~h}\left(4.69 \mathrm{Kj} / \mathrm{m}^{2}\right)$; there were four apple fruit per exposure time. After exposure to UV-B radiation, the four apple fruit from each exposure time were placed separately in a plastic bag containing 1 liter of KPBT wash buffer $\left(\mathrm{KH}_{2} \mathrm{PO}_{4}[0.05 \mathrm{M}], \mathrm{K}_{2} \mathrm{HPO}_{4}[0.05 \mathrm{M}]\right.$, and $0.05 \%$ (wt/vol] Tween 80, pH 6.5) and were shaken at $120 \mathrm{rpm}$ for $20 \mathrm{~min}$. An aliquot of $5 \mathrm{ml}$ was recovered and serially diluted in KPBT wash buffer. A $100-\mu l$ aliquot from each dilution, including stock, was spread in triplicates onto a selective medium (HST-PDA: Sumico at $2.5 \mathrm{mg} / \mathrm{ml}$, tetramethyl thiuram disulfide [TMTD] at 0.25 $\mathrm{mg} / \mathrm{ml}$, and hygromycin at $416 \mathrm{mg} / \mathrm{ml}$ ) and then incubated for $72 \mathrm{~h}$ at $25^{\circ} \mathrm{C}$ before colonies were counted. This experiment was conducted twice, and the results were expressed as mortality rates (percent).

In vitro screening of $\mathrm{UV}$ protectants. The following UV protectants were evaluated for their effect on the survival of yeast strain K exposed to UV-B radiation: congo red (21) (0.1\%), tryptophan (22) $(0.1 \%)$, riboflavin (27) (1\%), lignin (0.5\% sodium lignate $+0.05 \%$ calcium chloride), casein (2) $(0.5 \%)$, gelatine $(0.5 \%)$, folic acid (8) (1\%), tyrosine (22) (1\%), formula $1(0.1 \%$ congo red $+0.1 \%$ tryptophan), formula $2(1 \%$ folic acid $+0.5 \%$ tyrosine + $0.5 \%$ riboflavin $)$, formula $3(0.5 \%$ folic acid $+1 \%$ tyrosine $+0.5 \%$ riboflavin), and formula $4(0.5 \%$ folic acid $+0.5 \%$ tyrosine $+1 \%$ riboflavin). The UV protectants were prepared in SDW.

Strain K was adjusted to $1 \times 10^{7} \mathrm{CFU} / \mathrm{ml}$, mixed with each UV protectant, and exposed to UV-B radiation for $0,0.5,1,1.5,2$, or 2.5 h. For each exposure time, an unexposed strain K without UV protectant was kept in darkness. A suspension of strain $\mathrm{K}$ without UV protectant but exposed to UV-B radiation served as the UV-B control. After exposure to UV-B radiation, each suspension was transferred to a 50-ml Falcon tube and then 10-fold serially diluted in SDW. For each dilution, including stock cultures, $100 \mu \mathrm{l}$ was spread in triplicates onto PDA petri dishes and then incubated for $72 \mathrm{~h}$ at $25^{\circ} \mathrm{C}$ before colonies were counted. This experiment was repeated twice. The average viability (percentage) of antagonistic yeast cells for each UV protectant was calculated with the following formula: viability $(\%)=[($ colony number in the presence of UV protectant)/(colony number in unexposed medium without UV protectant) $] \times 100$.

In vivo screening of $\mathbf{U V}$ protectants. Using the same protocol described for in vivo screening without UV protectants, apple fruit were treated with strain $\mathrm{K}\left(1 \times 10^{8} \mathrm{CFU} / \mathrm{ml}\right)$ alone or in combination with the UV protectants (Table 1) and exposed to $3 \mathrm{~h}$ of UV-B radiation; we used four apple fruit for each UV protectant. Strain K was recovered from the fruit surface and colonies were counted as described for the in vivo influence of UV-B radiation on UV-pro- 
tectant performance. Viability was calculated for each combination strain K-UV protectant with the formula described earlier. This experiment was conducted twice.

Effect of UV protectants on biocontrol of $P$. expansum by strain $\mathbf{K}$ on wounded apple fruit. Disinfected apple fruit were wounded (two wounds per fruit) with a cork borer (4 $\mathrm{mm}$ in diameter and $2 \mathrm{~mm}$ deep) at the equatorial zone of each fruit. Suspensions of strain $\mathrm{K}$ were prepared as described above. Each wound was treated with $50 \mu$ of strain $\mathrm{K}\left(1 \times 10^{7} \mathrm{CFU} / \mathrm{ml}\right)$ with $\mathrm{UV}$ protectant or with water. After drying, the fruit were stored in closed plastic boxes at $24^{\circ} \mathrm{C}$ for $24 \mathrm{~h}$ before pathogen inoculation. Treated fruit were inoculated with $50 \mu \mathrm{l}$ of a spore suspension of $P$. expansum at $1 \times 10^{4}$ spores $/ \mathrm{ml}$. The treated fruit were kept in the moistened closed plastic boxes with $3 \mathrm{ml}$ of SDW at $24^{\circ} \mathrm{C}$ for seven additional days, at which time the incidence (percentage) of decayed apple fruit and infected wounds of fruit per treatment were evaluated at each replicate and compared with the untreated treatment. There were three replicates with five apple fruit (10 wounds per replicate) for each treatment. This experiment was repeated twice.

Statistical analysis. For the first in vitro and in vivo experiments (experiments without UV protectants), the mortality data (percent) corresponding to the in vitro UV-B doses $0.46,0.93$, 1.87 , and $2.33 \mathrm{Kj} / \mathrm{m}^{2}$ and the in vivo UV-B doses $0.93,1.87,2.79$, 3.74 , and $4.68 \mathrm{Kj} / \mathrm{m}^{2}$ were transformed to probit mortality $(Y)$ using conversion tables (5) and then plotted against UV-B $(X)$ dose using the linear equation $Y=a X+b$, in which $a=$ the increase of $Y$ per unit increase of $X$, and $b=$ the intercept). This regression equation was used to estimate the 50 and $90 \%$ lethal dose $\left(\mathrm{LD}_{50}\right.$ and $\mathrm{LD}_{90}$, respectively) values. Regression coefficients ( $\mathrm{a}$ and $\mathrm{b}$ ) were estimated using the linear regression procedure of SAS (SAS Institute, Cary, NC). Data for strain K viability (percent) and efficacy (experiments with UV protectants) were transformed to logarithms to improve homogeneity of variances (30), and were subjected to the analysis of variance procedure of SAS. Because the variances from both independent experiments of in vitro $(P=0.99)$ and in vivo $(P=0.99)$ viability, incidence of infected fruit $(P=0.91)$, and infected wounds per fruit $(P=0.96)$ were homogenous according to Bartlett's test and there was no significant interaction effect between treatment and replicate, data from both independent experiments were pooled and analyzed together. Means were compared using Tukey's studentized range test. In all analyses, statistical significance was judged at $\alpha=0.05$.

\section{Results}

In vitro and in vivo influence of UV-B radiation on survival of strain $\mathbf{K}$. The in vitro mortality of strain $\mathrm{K}$ increased from $12 \%$ after $0.5 \mathrm{~h}\left(0.46 \mathrm{Kj} / \mathrm{m}^{2}\right)$ of exposure to UV-B radiation to $100 \%$ after $2 \mathrm{~h}\left(1.87 \mathrm{Kj} / \mathrm{m}^{2}\right)$ of exposure (Fig. 1A). The UV-B dose explained $93 \%\left(Y=2.06 X+3.18, R^{2}=0.93\right)$ of probit variation. Based on the regression of probit mortality on dose, the in vitro $\mathrm{LD}_{50}$ and $\mathrm{LD}_{90}$ values were 0.89 and $1.6 \mathrm{Kj} / \mathrm{m}^{2}$, respectively. These values correspond to 0.39 and $0.69 \mathrm{~h}$ of natural sunlight.

The in vivo mortality rates were much lower than the in vitro rates. Where $2 \mathrm{~h}\left(1.87 \mathrm{Kj} / \mathrm{m}^{2}\right)$ of exposure caused $100 \%$ mortality in vitro (Fig. 1A), this exposure caused only $33 \%$ mortality in vivo (Fig. 1B). The strain $\mathrm{K}$ mortality reached 50 and $75.1 \%$ after $3 \mathrm{~h}$ $\left(2.79 \mathrm{Kj} / \mathrm{m}^{2}\right)$ and $4 \mathrm{~h}\left(3.74 \mathrm{Kj} / \mathrm{m}^{2}\right)$, respectively, of exposure. The in vivo $\mathrm{LD}_{50}$ and $\mathrm{LD}_{90}$ values were 3.20 and $5.76 \mathrm{Kj} / \mathrm{m}^{2}(Y=0.50$ $\left.X+3.4, R^{2}=0.94\right)$. These values correspond to 1.35 and $2.42 \mathrm{~h}$ of natural sunlight. The UV-B dose explained $94 \%$ of the probit variation. In both in vitro and in vivo linear probit models, UV-B doses had a positive linear effect on the mortality of strain K.

In vitro screening of UV protectants. All compounds significantly reduced the mortality of strain $\mathrm{K}$ when the yeast was exposed to UV-B radiation in vitro (Fig. 2). The most effective UV protectants were formula 2, riboflavin, formula 3, formula 4 , folic acid, lignin, gelatine, and tyrosine. The viability of strain $\mathrm{K}$ was significantly increased by all UV protectants compared with the control but best results were observed with riboflavin and formulas 2 to 4 (Fig. 3A).
In vivo screening of $\mathbf{U V}$ protectants. Relative to the control (strain $\mathrm{K}$ alone), riboflavin, folic acid, gelatine, tyrosine, lignin, tryptophan, and formulas 1,2 , and 4 significantly increased the viability of strain $\mathrm{K}$ when the yeast was exposed to UV-B radiation in vivo. Formula 3, congo red, and casein failed to increase the viability of strain $\mathrm{K}$ when the yeast was exposed to UV-B radiation in vivo (Fig. 3B). The highest viability of strain $\mathrm{K}$ was obtained with riboflavin, which exceeded $100 \%$.

Effect of UV protectants on biocontrol of $P$. expansum by strain K on wounded apple fruit. Strain K reduced significantly the incidence of decayed apple fruit and the number of infected wounds due to $P$. italicum by about 83 and $90 \%$, respectively. Many UV protectants, including riboflavin, congo red, tryptophan, casein, gelatine, tyrosine, and formulas 1 to 4 significantly reduced the efficacy of strain $\mathrm{K}$. The combination of strain $\mathrm{K}$ with lignin or folic acid increased significantly the efficacy of disease control relative to the strain $\mathrm{K}$ alone (Table 1). In those treatments, no infected fruit and wounds were observed.

\section{Discussion}

Preharvest application of microbial agents can be an alternative method to chemical control for postharvest disease management $(3,7,30,43)$. The biocontrol agent competes with the pathogen and colonizes the fruit wounds. Applying the control agent before harvest can reduce the initial infection which could be induced during transportation and harvesting and suppress pathogen growth during storage (24). The field environment, however, can reduce the control agent's survival and efficacy. For example, Lahlali et al. (30) found a high variation in the efficacy of strain $\mathrm{K}$ when applied preharvest during two successive seasons and attributed this variation to the microclimate.

The research presented here is the first detailed investigation on the effects of UV-B radiation and UV protectants on an antagonistic yeast. Our results show that the population density of strain $\mathrm{K}$
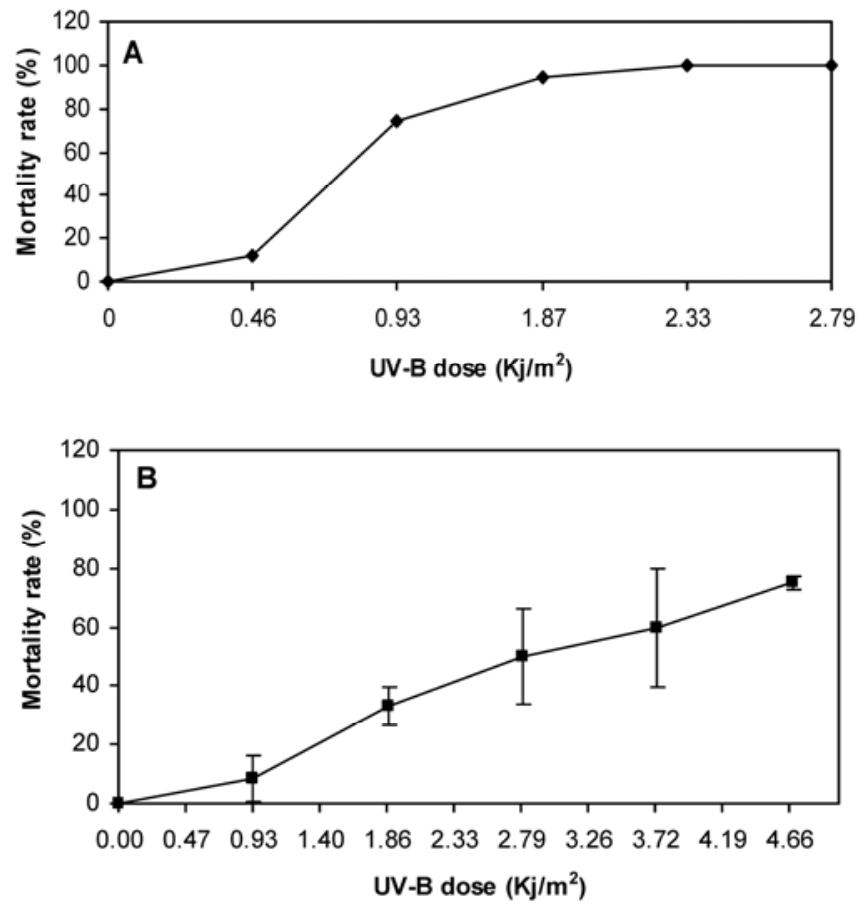

Fig. 1. A, In vitro and $B$, in vivo mortality of the yeast strain $K$ after exposure to UV$B$ radiation. Mortality is expressed as percentages. Shown are the mean values $( \pm$ standard error) of combined datasets of two independent experiments with three replicates each time. Strain $\mathrm{K}$ was exposed in vitro to UV-B radiation for $0 \mathrm{~h}(0$ $\left.\mathrm{Kj} / \mathrm{m}^{2}\right), 0.50 \mathrm{~h}\left(0.46 \mathrm{Kj} / \mathrm{m}^{2}\right), 1 \mathrm{~h}\left(0.93 \mathrm{Kj} / \mathrm{m}^{2}\right), 2 \mathrm{~h}\left(1.87 \mathrm{Kj} / \mathrm{m}^{2}\right), 2.50 \mathrm{~h}\left(2.33 \mathrm{Kj} / \mathrm{m}^{2}\right), 3$ $\mathrm{h}\left(2.79 \mathrm{Kj} / \mathrm{m}^{2}\right)$, or $4 \mathrm{~h}\left(3.74 \mathrm{Kj} / \mathrm{m}^{2}\right)$ and in vivo to UV-B radiation for $0 \mathrm{~h}\left(0 \mathrm{Kj} / \mathrm{m}^{2}\right), 1 \mathrm{~h}$ $\left(0.93 \mathrm{Kj} / \mathrm{m}^{2}\right), 2 \mathrm{~h}\left(1.87 \mathrm{Kj} / \mathrm{m}^{2}\right), 3 \mathrm{~h}\left(2.79 \mathrm{Kj} / \mathrm{m}^{2}\right), 4 \mathrm{~h}\left(3.74 \mathrm{Kj} / \mathrm{m}^{2}\right)$, or $5 \mathrm{~h}\left(4.69 \mathrm{Kj} / \mathrm{m}^{2}\right]$. The linear regression equation was used to calculate the 50 and $90 \%$ lethal dose values. 
declined with increased exposure to UV-B radiation both in vitro and in vivo. The population dropped to $10 \%$ after a UV-B exposure of only $1.6 \mathrm{Kj} / \mathrm{m}^{2}$ (equivalent to $0.69 \mathrm{~h}$ of natural sunlight) in vitro and after $5.76 \mathrm{Kj} / \mathrm{m}^{2}$ (equivalent to $2.46 \mathrm{~h}$ of natural sunlight) in vivo. Barga et al. (6) reported that the viability of the entomopathogenic fungus Verticillium lecanii declined to zero after a 4-h exposure to artificial sunlight. Hadapad et al. (18) reported a complete loss in the viability of Bacillus sphaericus spores after $6 \mathrm{~h}$ of exposure to artificial sunlight. Using another Bacillus mutant strain, Riesenman and Nicholson (38) documented a relatively high $\mathrm{LD}_{90}$ value for UV-B exposure (ranging from 28 to $31 \mathrm{Kj} / \mathrm{m}^{2}$ ). Relative to the organisms in these other studies, strain $\mathrm{K}$ was highly sensitive to sunlight. If the current results were representative of orchard conditions, a population of strain $\mathrm{K}$ could disappear from the fruit surface (but not necessarily from colonized wounds) within $4 \mathrm{~h}$ after its application. Researchers have recommended that such antagonists be applied $48 \mathrm{~h}$ before harvest; during some part of that 48-h period, environmental conditions would presumably allow the antagonist to colonize wounds quickly and compete with pathogens and other microorganisms on the fruit surface (30). Any additives that would increase the survival of strain $\mathrm{K}$ on fruit surfaces would be valuable.

The addition of riboflavin, folic acid, lignin, tyrosine, and gelatine as UV protectants increased most the in vitro and in vivo survival of strain K. Such chemicals may prevent the harmful effects of UV-B radiation if the antagonist was applied preharvest. The inclusion of such UV protectants in formulations might extend the life of the biocontrol agent but field trials will have to be conducted to support this hypothesis. Lignin and gelatine can increase the longevity of microbial control agents by protecting them against UV-B radiation and by reducing wash-off (40). In contrast, congo red and tryptophan acted as UV-A or UV-B absorbers $(21,22)$. Casein reduced mortality caused by UV-B radiation and reduces wash-off (2).

The performance of strain $\mathrm{K}$ in combination with UV protectants and their mixtures was largely comparable between in vitro and in vivo experiments; however, there were differences in the level of protection. For example, formula 2 increased protection in both assays but performed better in vitro than in vivo. It is possible that hydrophobic interactions between the epidermal layer of apple fruit and strain $\mathrm{K}$ with or without $\mathrm{UV}$ protectant played a role in this difference. The $10 \%$ sodium hypochlorite treatment or damages induced by UV-B radiation stimulus may have altered or removed the natural cuticular waxes from the upper apple fruit, which may have increased the absorption of UV protectants into the cuticle (depending on molecular weight). Hadapad et al. (17) found a great variability in the viability of Bacillus sp. spores when treated with UV protectants; they also reported that riboflavin and congo red were more effective than folic acid and gelatine. Others reported that congo red increased the viability of Beauvaria bassiana and $B$. thuringiensis $(11,23)$. In contrast, congo red performed poorly in our study with strain $\mathrm{K}$. We suspect that the efficacy of the UV protectants could depend on the organism that they are protecting.

In the biocontrol experiment with wounded apple fruit, strain $\mathrm{K}$ provided almost complete control (i.e., 90\%) against $P$. expansum. In previous studies, this yeast provided 80 to $100 \%$ control of $P$. expansum and other postharvest fruit pathogens, depending on the

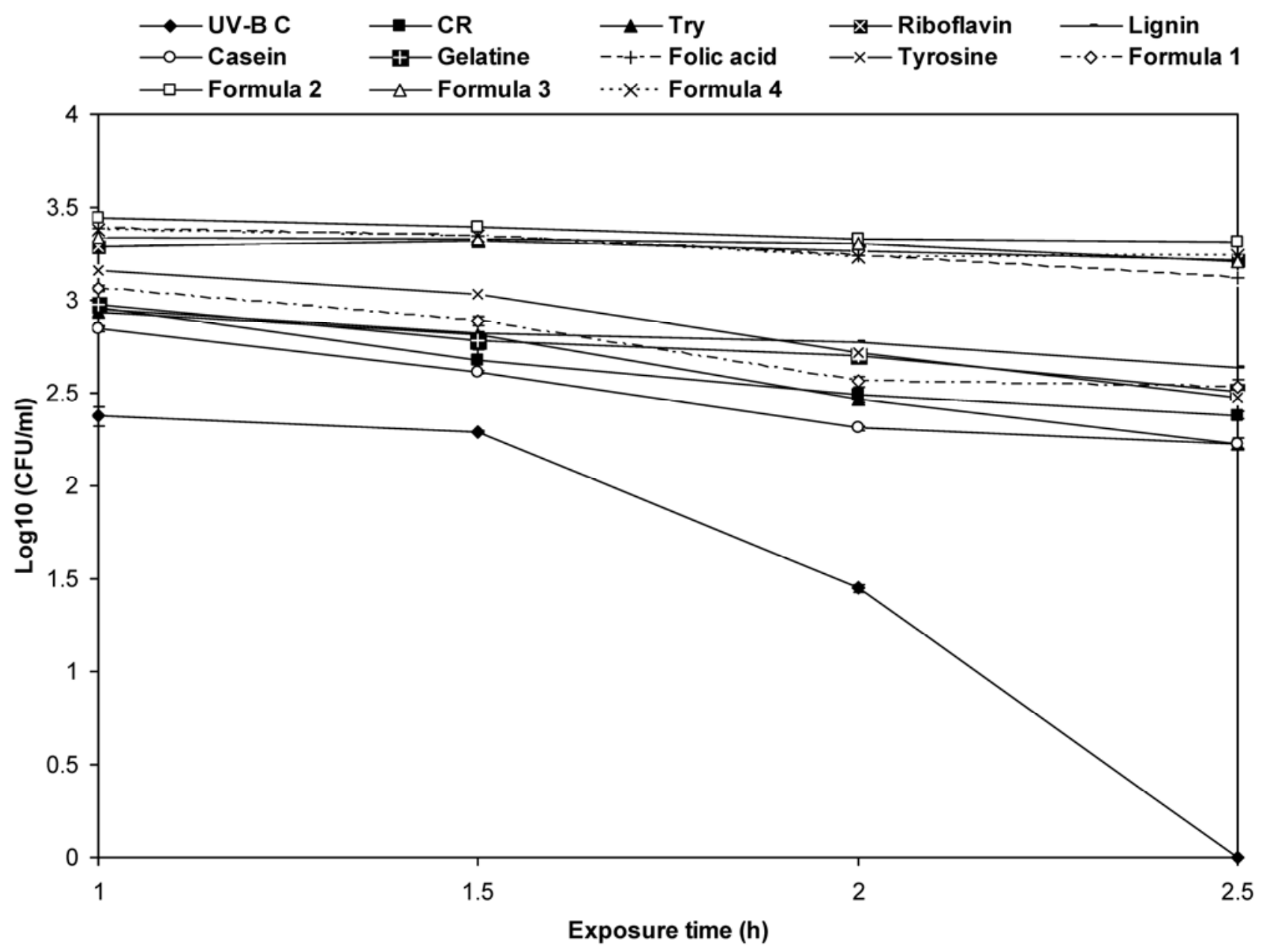

Fig. 2. In vitro survival of the yeast strain $\mathrm{K}$ after exposure to UV-B radiation (for 1.0, 1.5, 2.0, or $2.5 \mathrm{~h}$ ) and as affected by UV protectants. Shown are the mean values ( \pm standard error) of combined datasets of two independent experiments with three replicates each time. UV-B C = strain K exposed to UV-B radiation in the absence of a UV protectant, $\mathrm{CR}=$ congo red, Try = tryptophan, formula $1=0.1 \%$ congo red $+0.1 \%$ tryptophan, formula $2=1 \%$ folic acid $+0.5 \%$ tyrosine $+0.5 \%$ riboflavin, formula $3=0.5 \%$ folic acid $+1 \%$ tyrosine $+0.5 \%$ riboflavin, and formula $4=0.5 \%$ folic acid $+0.5 \%$ tyrosine $+1 \%$ riboflavin . 
concentration of yeast applied, the time elapsed after its application, and the specifics of pathogen inoculation and pathogen pressure $(26,30,32)$. Even better control in the current study could have resulted from the use of freshly harvested apple fruit or lower pathogen pressure. Riboflavin, congo red, tryptophan, casein, gelatine, tyrosine, and formulas 1 to 4 negatively affected the performance of strain $\mathrm{K}$ on wounded apple fruit not exposed to UV-B radiation. Why these UV protectants increased survival rates but did not enhance biocontrol warrants investigation. Maybe these compounds only enhance biocontrol when the yeast is exposed to UV-B radiation. It is unclear if lignin and folic acid can increase strain $\mathrm{K}$ performance. Experiments with lower levels of strain $\mathrm{K}$ performance may allow mean separation and, thus, help clarify this point.

Apple fruit at early stages of development are protected by a thin, waxy cuticle, which grows and forms the platelets that appear to be standing on freshly harvested fruit. Even after harvest and cold storage at $4{ }^{\circ} \mathrm{C}$, these wax platelets continue to grow, albeit at a reduced rate $(13,36,41)$. Therefore, applying strain $\mathrm{K}$ in combination with UV protectants as a preharvest treatment on the tree or immediately after harvest could affect the status of the natural wax cuticle. These treatments might adhere to natural wax cuticle and form another layer, which is completely different and thicker than when the same treatments are applied to stored apple fruit. Therefore, our in vivo and biocontrol findings could have been affected by the changes occurring in cuticular wax layer during preharvest treatment. Several reports underlined a higher variation in cuticular wax of apple fruit topography following variations in environmental conditions (higher temperature, sunlight, and water stress) or preharvest chemicals treatments (16).

In summary, the antagonist yeast strain $\mathrm{K}$ was highly susceptible to UV-B radiation both in vitro and in vivo. Whether UV protectants can increase the efficacy of strain $\mathrm{K}$ is still unclear; however, some compounds increased the survival of strain $\mathrm{K}$ in petri dish assays or on apple fruit exposed to UV-B radiation. Lignin, folic acid, riboflavin, tryptophan, congo red, formula 1, and formula 2 should be further investigated as UV protectants for the preharvest application of strain $\mathrm{K}$ as a biocontrol agent of postharvest disease.

\section{Acknowledgments}

We thank F. Dresen (Gembloux Agro-Biotech) for UV-B radiation chamber preparation and biocontrol trials, E. Pouillard for technical assistance, and B. Jaffee (University of California at Davis) for manuscript editing.

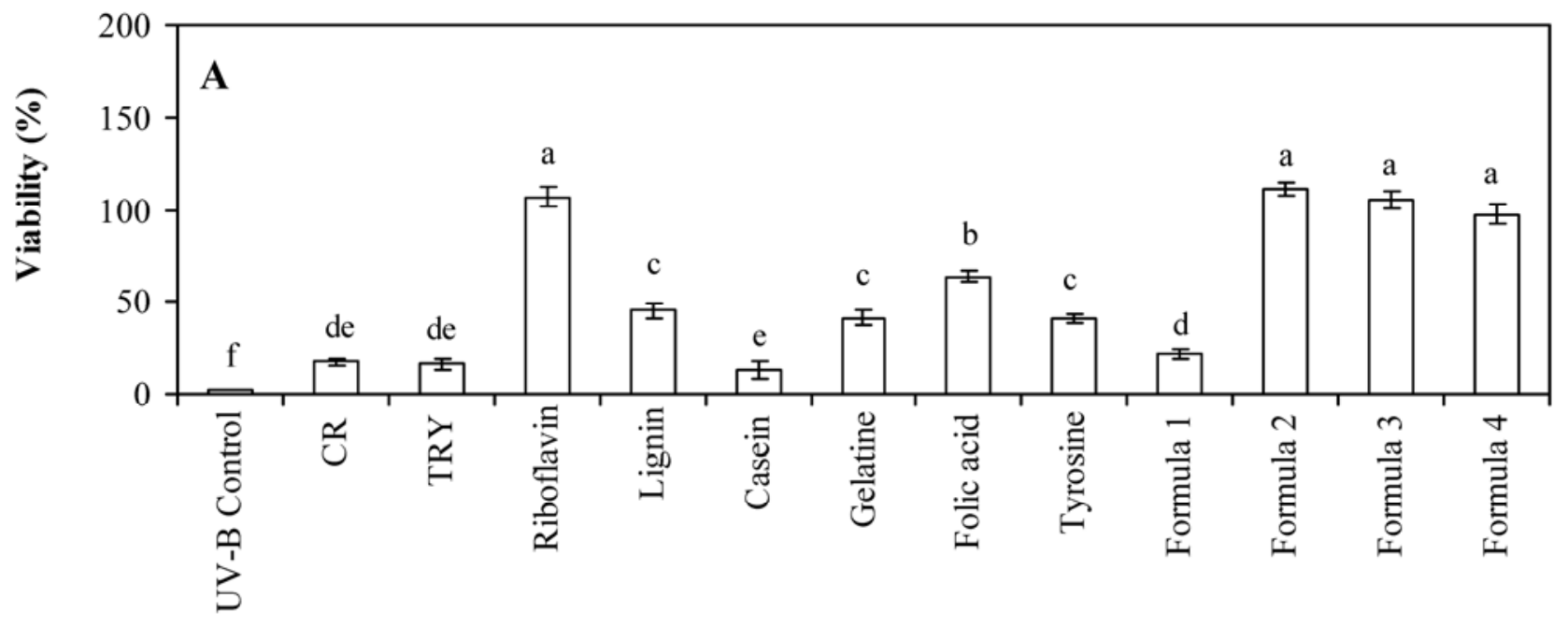

Treatment

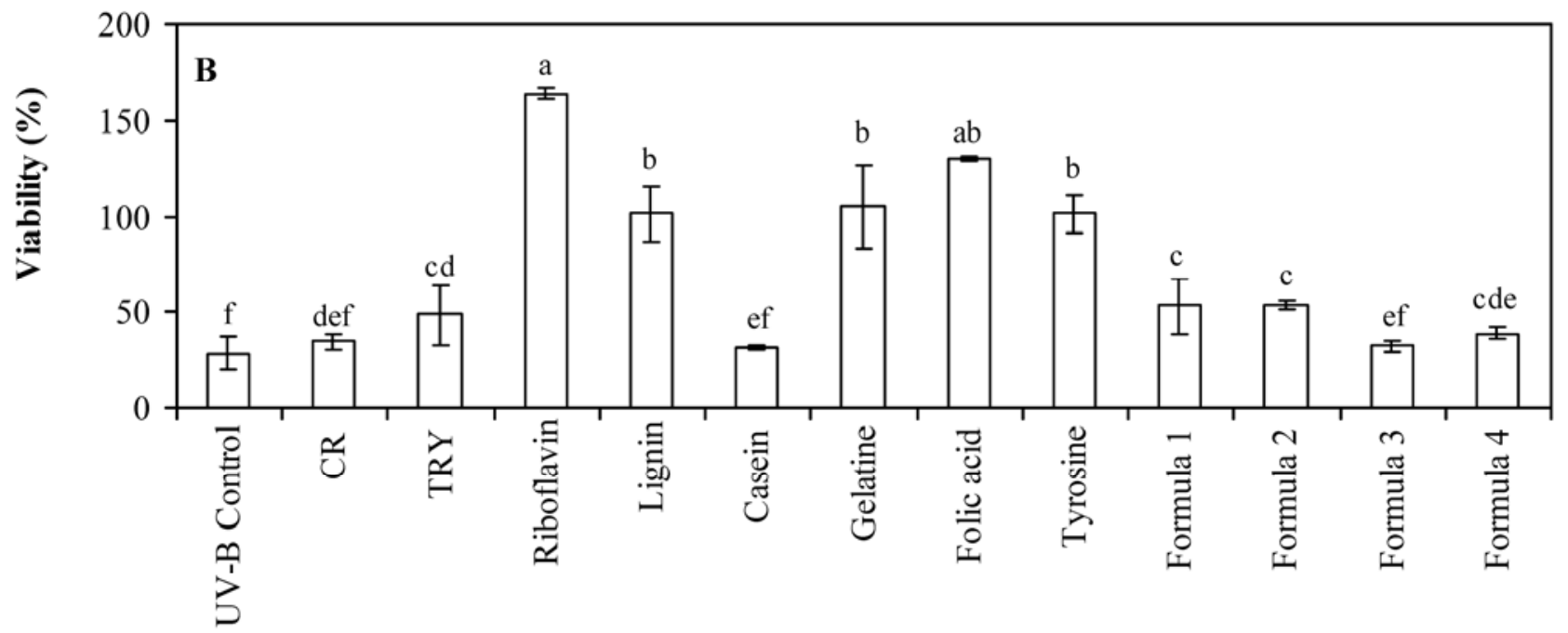

Treatment

Fig. 3. Yeast strain $\mathrm{K}$ survival after $\mathbf{A}$, in vitro and $\mathbf{B}$, in vivo exposure to UV-B radiation for 2.0 and $3 \mathrm{~h}$, respectively, and as affected by UV protectants. Shown are the mean values ( \pm standard error) of combined datasets of two independent experiments with three replicates. Treatments with the same letters are not significantly different according to Tukey's test $(\alpha=0.05)$. UV-B $C=$ the control that was exposed to UV-B radiation in the absence of a UV protectant, $C R=$ congo red, Try $=$ tryptophan, formula $1=0.1 \%$ congo red $+0.1 \%$ tryptophan, formula $2=1 \%$ folic acid $+0.5 \%$ tyrosine $+0.5 \%$ riboflavin, formula $3=0.5 \%$ folic acid $+1 \%$ tyrosine $+0.5 \%$ riboflavin, and formula $4=0.5 \%$ folic acid $+0.5 \%$ tyrosine $+1 \%$ riboflavin. 


\section{Literature Cited}

1. Agrios, G. N. 1997. Plant Pathology, 4th ed. Academic Press, San Diego, CA.

2. Behle, R. W., McGuire, M. R., and Shasha, B. S. 1996. Extending the residual toxicity of Bacillus thuringiensis with casein-based formulations. J. Econ. Entomol. 89:1399-1405.

3. Benbow, J. M., and Sugar, D. 1999. Fruit surface colonization and biological control of post-harvest diseases of pear by pre-harvest yeast applications. Plant Dis. 83:839-844

4. Bertrand, P. F., and Saulie-Carter, J. L. 1978. The occurrence of benomyltolerant strains of Penicillium expansum and Botrytis cinerea in mid Columbia region of Oregon and Washington. Plant Dis. Rep. 62:305-320.

5. Bliss, C. I. 1934. The methods of probits. Science 79:38-39.

6. Braga, G. U., Rangel, D. E. N., Flint, S. D., Miller, C. D., Anderson, A. J., and Roberts, D. W. 2002. Damage and recovery from UV-B exposure in conidia of the entomopathogens Verticillium lecanii and Aphanocladium album. Mycologia 94:912-920.

7. Cañamás, T. P., Viñas, I., Usall, J., Torres, R., Anguera, M., and Teixidó, N. 2008. Control of postharvest diseases on citrus fruit by preharvest applications of biocontrol agent Pantoea agglomerans CPA-2: Part II. Effectiveness of different cell formulations. Postharvest Biol. Technol. 49:96-106.

8. Chapiro, M. 1985. Effectiveness of B vitamins as UV-screens for the gypsy moth (Lepidoptera Lymantridae) nuclear polyhedrosis virus. Environ. Entomol. 14:705-708

9. De Clercq, D., Cognet, S., Pujol, M., Lepoivre, P., and Jijakli, M. H. 2003. Development of a SCAR marker and a semi-selective medium for specific quantification of Pichia anomala strain K on apple fruit surfaces. Postharvest Biol. Technol. 29:237-247.

10. Droby, S., Chalutz, E., and Wilson, C. L. 1991. Antagonistic microorganisms as biocontrol agents of postharvest diseases of fruit and vegetables. Postharvest News Inf. 2:169-173.

11. Dunkle, M., and Shasha, B. S. 1989. Response of starch-encapsulated Bacillus thuringiensis containing ultraviolet screens to sunlight. Entomological 18:1035-1041.

12. Eckert, J. W., and Ogawa, J. M. 1988. The chemical control of postharvest diseases: deciduous fruit, berries, vegetables and root/tuber crops. Annu. Rev. Phytopathol. 26:433-469.

13. Freeman, B., Albrigo, L. G., and Biggs, R. H. 1979. Ultrastructure and chemistry of cuticular waxes of developing citrus leaves and fruit. J. Am. Soc. Hortic. Sci. 104:801-808.

14. Friel, D., Pessoa, N. M., Vandenbol, M., and Jijakli, M. H. 2007. Separate and combined disruptions of two exo-beta-1,3-glucanase genes decrease the efficiency of Pichia anomala (strain K) biocontrol against Botrytis cinerea on apple. Mol. Plant-Microbe Interact. 20:371-379.

15. Garcia, J. M., Aguilera, C., and Albi, M. A. 1995. Post-harvest treatment on Spanish strawberry (Fragaria $\times$ ananassa cv. Tudla). J. Agric. Food Chem. 43:1489-1492.

16. Glenn, G. M., Poovaiah, B. W., and Rasmussen, H. P. 1985. Pathways of calcium penetration through isolated cuticles of golden delicious apple fruit. J. Am. Soc. Hortic. Sci. 110:166-171.

17. Hadapad, A. B., Hire, R. S., Vijayalakshmi, N., and Dongre, T. K. 2009. UV-protectants for the biopesticide based on Bacillus sphaericus Neide and their role in protecting the binary toxins from UV-radiation. J. Invertebr. Pathol. 100:147-152.

18. Hadapad, A. B., Vijayalakshmi, N., Hire, R. S., and Dongre, T. K. 2008. Effect of ultraviolet radiation on spore viability and mosquitocidal activity of an indigenous ISPC-8 Bacillus sphaericus Neide strain. Acta Trop. 107:113-116.

19. Harman, G. E., Obregon, M. A., Samuels, G. J., and Lorito, M. 2010. Changing models for commercialization and implementation of biological in the developing and the developed world. Plant Dis. 94:928-939.

20. Homes, G. J., and Eckert, J. W. 1999. Sensitivity of Penicillium digitatum and $P$. italicum to postharvest citrus fungicides in California. Phytopathology 89:716-721.

21. Ignoffo, C. M., and Garcia, C. 1995. Aromatic/heterocyclic amino acids and the simulated sunlight-ultraviolet inactivation of the Heliothis/Helicoverpa baculovirus. Environ. Entomol. 24:480-482.

22. Ignoffo, C. M., Shasha, B. S., and Shapiro, M. 1991. Sunlight ultraviolet protection of the Heliothis Nuclear Polyhedrosis Virus through starch-encapsulation technology. J. Invertebr. Pathol. 57:134-136.

23. Inglis, G. D., Goettel, M. S., and Johnson, D. L. 1995. Influence of ultraviolet light protectants on persistence of the entomopathogenic fungus, Beauveria bassiana. Biol. Control 5:581-590.

24. Ippolito, A., and Nigro, F. 2000. Impact of pre-harvest application of biological control agents on post-harvest diseases of fresh fruit and vegetables. Crop Prot. 19:610-619.
25. Jijakli, M. H., and Lepoivre, P. 1998. Characterization of an Exo-beta-1,3 Glucanase produced by Pichia anomala Strain K, antagonist of Botrytis cinerea on apples. Phytopathology 88:335-343.

26. Jijakli, M. H., Lepoivre, P., Tossut, P., and Thonard, P. 1993. Biological control of Botrytis cinerea and Penicillium expansum sp. on post-harves apples by two antagonistic Meded. Fac. Landbouwwet. Rijksuniv. Gent 58/3b:1349-1358.

27. Killick, H. J. 1990. Influence of droplet size, solar ultraviolet light and protectants, and other factors on the efficacy of baculovirus sprays against Panolis flammea (Schiff.) (Lepidoptera: Noctuidae). Crop Prot. 9:21-28.

28. Lahlali, R., Bajji, M., Serrhini, M. N., and Jijakli, M. H. 2008. Modelling the effect of temperature, water activity and solute on the in vitro growth of the biocontrol yeast Pichia anomala strain K. Biotechnol. Agron. Soc. Environ. 12:353-359.

29. Lahlali, R., and Jijakli, M. H. 2009. Enhancement of the biocontrol agent Candida oleophila (strain $\mathrm{O}$ ) survival and control efficiency under extreme conditions of water activity and relative humidity. Biol. Control 51:403-408

30. Lahlali, R., Massart, S., De Clercq, D., Serrhini, M. N., Creemers, P., and Jijakli, M. H. 2009. Assessment of Pichia anomala (strain K) efficacy against blue mould of apples when applied pre- or post-harvest under laboratory conditions and in orchard trials. Eur. J. Plant Pathol. 123:37-45.

31. Lahlali, R., Massart, S., Serrhini, M. N., and Jijakli, M. H. 2008. A BoxBehnken design for predicting the combined effects of relative humidity and temperature on antagonistic yeast population density at the surface of apples. Int. J. Food Microbiol. 122:100-108.

32. Lahlali, R., Serrhini, M. N., and Jijakli, M. H. 2004. Efficacy assessment of Candida oleophila (strain $\mathrm{O}$ ) and Pichia anomala (strain K) against major postharvest diseases of citrus fruit in Morocco. Commun. Agric. Appl. Biol. Sci. 69:601-609.

33. Massart, S., and Jijakli, M. H. 2006. Identification of differentially expressed genes by cDNA-amplified fragment length Polymorphism in the biocontrol agent Pichia anomala (Strain Kh5). Phytopathology 96:80-86.

34. Melendez, M. R. 2002. Études des facteurs écologiques et physiologiques influençant le niveau de protection biologique apporté par deux souches de levures sur pommes vis-à-vis de Botrytis cinerea et Penicillium sp. Mémoire de fin d'études. Mc thesis, FUSAGx, Belgium.

35. Morales, H., Marin, S., Ramos, A. J., and Sanchis, V. 2010. Influence of postharvest technologies applied during cold storage of apples in Penicillium expansum growth and patulin accumulation: a review. Food Control 21:953-962.

36. Petracek, P. D., and Bukovac, M. J. 1995. Rheological properties of enzymatically isolated tomato fruit cuticle. Plant Physiol. 109:675-679.

37. Pujol, M., De Clercq, D., Cognet, S., Lepoivre, P., and Jijakli, M. H. 2003. Monitoring system for the biocontrol agent Pichia anomala strain K using quantitative competitive PCR-ELOSA. Plant Pathol. 53:103-109.

38. Riesenman, P. J., and Nicholson, W. L. 2000. Role of the spore coat layers in Bacillus subtilis spore resistance to hydrogen peroxyde, artificial UV-C, UV-B, and solar UV-radiation. Appl. Environ. Microbiol. 66:620-626.

39. Rosset, P. M. 1997. Cuba: ethics, biological control, and crisis. Agric. Hum. Values 14:291-302

40. Spotts, R. A., and Cervantes, L. A. 1986. Populations, pathogenicity and benomyl resistance of Botrytis spp., Penicillium spp. and Mucor piriformis in packinghouses. Plant Dis. 70:106-108.

41. Storey, R., and Price, W. E. 1999. Microstructure of the skin of d'agen plums. Sci. Hortic. 81:279-286.

42. Tamez-Guerra, P., McGuire, M. R., Behle, R. W., Shasha, B. S., and Pingel, R. L. 2002. Storage stability of Anagraph falcifera nucleopolyhedrovirus in spray-dried formulations. J. Invertebr. Pathol. 79:7-16.

43. Teixido, N., Usall, J., and Vinas, I. 1999. Efficacy of preharvest and postharvest Candida sake biocontrol treatments to prevent blue mould on apples during cold storage. Int. J. Food. Microbiol. 50:203-210.

44. Teixido, N., Vinas, I., Usall, J., and Magan, N. 1998. Control of blue mold of apples by pre-harvest application of Candida sake grown in media with different water activity. Phytopathology 88:960-964.

45. Vinas, I., Usall, J., and Sanchis, V. 1991. Tolerance of Penicillium expansum to postharvest fungicides treatments in apples packinghouses in Lerida (Spain). Mycopathologia 113:15-18.

46. Vinas, I., Usall, J., and Sanchis, V. 1993. Imazalil resistant Penicillium isolates from Spanish apple packinghouses. Mycopathologia 123:27-33.

47. Wilson, C. L., and Wisniewski, M. E., eds. 1994. Biological Control of Post-harvest Diseases: Theory and Practice. CRC Press, Boca Raton, FL.

48. Wilson, C. L., and Wisniewski, M. E. 1989. Biological control of postharvest diseases. Annu. Rev. Phytopathol. 27:425-441.

49. Wisniewski, M. E., and Wilson, C. L. 1992. Biological control of postharvest disease of fruit and vegetables: recent advances. HortScience 27:9498 . 